\title{
$\delta$-Aminolaevulinic acid mediated photodynamic antimicrobial chemotherapy on Pseudomonas aeruginosa planktonic and biofilm cultures
}

\author{
Chia-Fen Lee ${ }^{\mathrm{a}}$, Chi-Jui Lee ${ }^{\mathrm{b}}$, Chin-Tin Chen ${ }^{\mathrm{c}}$, Ching-Tsan Huang ${ }^{\mathrm{a}, \mathrm{b}, *}$ \\ ${ }^{a}$ Institute of Microbiology and Biochemistry, National Taiwan University, Taipei 106, Taiwan, ROC \\ b Department of Biochemical Science and Technology, National Taiwan University, 1, Section 4, Roosevelt Road, Taipei 106, Taiwan, ROC \\ ${ }^{\mathrm{c}}$ Center for Optoelectronic Biomedicine, College of Medicine, National Taiwan University, Taipei 106, Taiwan, ROC
}

Received 12 December 2003; received in revised form 16 April 2004; accepted 18 April 2004

Available online 8 June 2004

\begin{abstract}
To demonstrate photodynamic antimicrobial chemotherapy (PACT) against planktonic and biofilm cultures of Pseudomonas aeruginosa, using photoporphyrin IX which could be endogenously synthesized by administrating $\delta$-aminolaevulinic acid ( $\delta$-ALA), and a light emitted diode (LED) array to photoactivate the photosensitizer. P. aeruginosa suspended cells or biofilms, grown on a rotating disk reactor, were treated by different concentrations of $\delta$-ALA in the dark for $1 \mathrm{~h}$, followed by LED irradiation for various time. Regrowth experiments were conducted by placed PACT-treated disks back to a sterile reactor. Viable cells were determined by serial dilution and plate counts. Both P. aeruginosa planktonic and biofilm cells were inhibited by PACT with light doses or photosensitizer concentrations increasing. Treatments of planktonic cells with $10 \mathrm{mM} \delta$-ALA and incident dose $240 \mathrm{~J} \mathrm{~cm}^{-2}$ or 7.5 $\mathrm{mM}$ ALA and incident dose $360 \mathrm{~J} \mathrm{~cm}^{-2}$ led to completely photoinactivation. No viable biofilm cells were found after treatment of 20 $\mathrm{mM} \delta$-ALA and incident dose $240 \mathrm{~J} \mathrm{~cm}^{-2}$. However, regrowth was observed once PACT-treated biofilms were put back to a sterile reactor. Regrowth could be prevented only if biofilm samples were treated PACT twice. $\delta$-ALA-mediated PACT on P. aeruginosa planktonic and biofilm cells was effective, though the detailed mechanism still required further investigation.
\end{abstract}

(c) 2004 Elsevier B.V. All rights reserved.

Keywords: Aminolaevulinic acid; Photodynamic; Protoporphyrin IX; Light emitted diode

\section{Introduction}

Antimicrobial infection has been a long-term challenge for researchers, especially when biofilms was taken into consideration. Microbial biofilms are implicated in many healthy problems such as increasing transfer resistance, deteriorating medical materials, and withstanding host immune responses [1]. It has been estimated that as many as $60 \%$ of bacterial infections treated by physicians in the developed world are related to biofilm formation [2]. Conventional methods of biofilm control relied on blocking bacteria from attach-

\footnotetext{
${ }^{*}$ Corresponding author. Tel.: +886-2-23634796; fax: +886-227037341.

E-mail address: cthuang@ntu.edu.tw (C.-T. Huang).
}

ment, mechanical removal of bacteria from the surface, or applying antimicrobial agents to stop bacterial growth. However, the biofilm cells were much more recalcitrant than their planktonic counterparts [3]. Researchers have known that biofilm formation and resistance are influenced by complex genetic regulation [4]. One of the most exciting developments about biofilm genetic regulation is cell-to-cell communication or known as quorum sensing [5]. Employing quorum sensing signal molecule analogs to jam bacterial intercellular communication and consequently block biofilm formation has been proved promising in biofilm control [6]. However, more detailed investigations on global regulatory networks of biofilm remain to be comprehended before effective application to eradicate biofilm [7]. 
Another potential alternative of biofilm control is photodynamic antimicrobial chemotherapy (PACT). PACT involves the application of photodynamic therapy (PDT), which employs the interaction between light and certain chemical photosensitizing agents (photosensitizers, PSs). After the target cells were treated with PS, irradiation with light of a suitable wavelength would excite PS to generate reactive oxygen species (ROS), especially singlet oxygen, and lead to oxidative damage [8]. As the improvement of light source and modification of natural and synthetic photosensitizers, PACT has shown remarkable antimicrobial effects against viruses [9,10], fungi [11], and bacteria [12]. Bertoloni et al. [13] demonstrated that the photocytotoxic activity of methicillin-resistant strains of Staphylococcus aureus (MRSA) treated with hematoporphyrin $(\mathrm{Hp})$ and 10 min irradiation, the survival fraction of MRSA fell by $99.9 \%$. All these reports showed that both wild types and antibiotic-resistant bacteria were suppressed by PACT. Although PACT has shown effective in planktonic cultures, only a few papers have reported PACT in biofilm cultures.

Wilson et al. [14] used aluminium disulphonated phthalocyanine $\left(\mathrm{AlPcS}_{2}\right)$ as the PS to treat Streptococcus sanguis biofilms and found no viable streptococci left following PACT with $12.2 \mathrm{~J}$ of laser light. Wood et al. [15] provided qualitative description of PACT against the natural oral plaque biofilms by confocal laser scanning microscopy (CLSM) and showed PACT causing loss of adhesion within the biofilm and subsequent loss of bulk biofilm. Employing CLSM to analysis multispecies biofilms after PACT treatment, O’Neill et al. [16] recently reported that the lethal photosensitization occurred predominantly in the outer layers of the stack leaving some of the innermost alive bacteria. This incomplete kill of PACT on biofilms might be attributed to the inability of the PS to transmit to these inner regions or the failure of light penetration into the biofilms, rather than the biofilm resistance mechanism per se.

In this paper, we demonstrated PACT against planktonic and biofilm cultures of Pseudomonas aeruginosa, using photoporphyrin IX (PpIX) which could be endogenously synthesized by administrating $\delta$-aminolaevulinic acid ( $\delta$-ALA) as the PS $[17,18]$. The cytotoxic activity of PACT on biofilm via endogenous PS and the regrowth of biofilm cells after PACT were also investigated.

\section{Materials and methods}

\subsection{Strain, medium, and precursor of photosensitizer}

Pseudomonas aeruginosa PAO1 was used in both planktonic and biofilm experiments. Tryptic Soy Broth (TSB; Difco, Detroit, MI, USA) was used as liquid medium throughout. To maintain the cell concentration at $10^{8}-10^{9}$ cells $\mathrm{ml}^{-1}, 1 / 10$ strength TSB was used for planktonic cultures. Biofilms were cultivated by continuously feeding $1 / 100$ strength TSB. Stock solution of $200 \mathrm{mM} \delta$-ALA (Sigma Chemical Co, St. Louis, MO, USA) in phosphate buffered saline (PBS, pH 7.0) solution was prepared instantly before use.

\subsection{Light source}

A light emitting diode (LED) array with a major wavelength of $630 \mathrm{~nm}$, designed by Industrial Technology Research Institute (Hsinchu, Taiwan), was used to excite photosensitizer. The fluence of light delivered was $100 \mathrm{~mW} \mathrm{~cm}^{-2}$.

\subsection{PACT on planktonic cultures}

Pseudomonas aeruginosa cells from the overnight culture were harvested by centrifuging at $1395 \mathrm{~g}$ for 10 min and resuspended into about $10^{8}$ cells $\mathrm{ml}^{-1}$ with sterile PBS. The resultant cell suspension was treated with $0,2.5,5,7.5,10$, and $12.5 \mathrm{mM}$ of $\delta$-ALA, respectively, in the dark for $1 \mathrm{~h}$. After $\delta$-ALA incubation, suspension was separated into two parts. One was irradiated by the LED subsequently for 20,40 , and $60 \mathrm{~min}$, while the other without irradiation was used as control.

\subsection{PACT on biofilm cultures}

A rotating disk reactor (Fig. 1), modified form the design of Pitts et al. [19], was used to cultivate $P$. aeruginosa biofilms. The reactor was made by a $500 \mathrm{ml}$ polypropylene container (Nalgene, Rochester, NY, USA) and consisted of a Teflon rotor and 24 removable $316 \mathrm{~L}$ stainless steel disks $(0.55 \mathrm{~cm}$ in diameter $)$ for sampling. The Teflon rotor was embedded with a magnetic stir bar on the bottom and was driven by a stirrer at $60 \mathrm{rpm}$. For each run, one $\mathrm{ml}$ of $P$. aeruginosa seed culture was transferred into $150 \mathrm{ml} \mathrm{1/10}$ strength TSB in the reactor and then stirred with the rotating rotor overnight to allow cell attachment. After incubation, the reactor was fed continuously with $1 / 100$ strength TSB at a rate of $615 \mathrm{ml} \mathrm{h}^{-1}$, a dilution rate of $4.1 \mathrm{~h}^{-1}$, for $24 \mathrm{~h}$ to reach the steady state.

The disks with mature biofilms were placed into a 48well multititer plate and then treated with $350 \mu \mathrm{l}$ of 0,5 , 10,20 , and $40 \mathrm{mM} \delta$-ALA, respectively, in the dark for $1 \mathrm{~h}$. Four disks treated with different concentrations of $\delta$-ALA were exposed to the LED for $20 \mathrm{~min}$. All of the samples exposed to either light or drug alone were put into test tubes containing $10 \mathrm{ml}$ PBS. The test tubes were vertexed for $1 \mathrm{~min}$ in order to remove the biofilms from the disks. The resultant suspension was used for both viable and total cell count. 


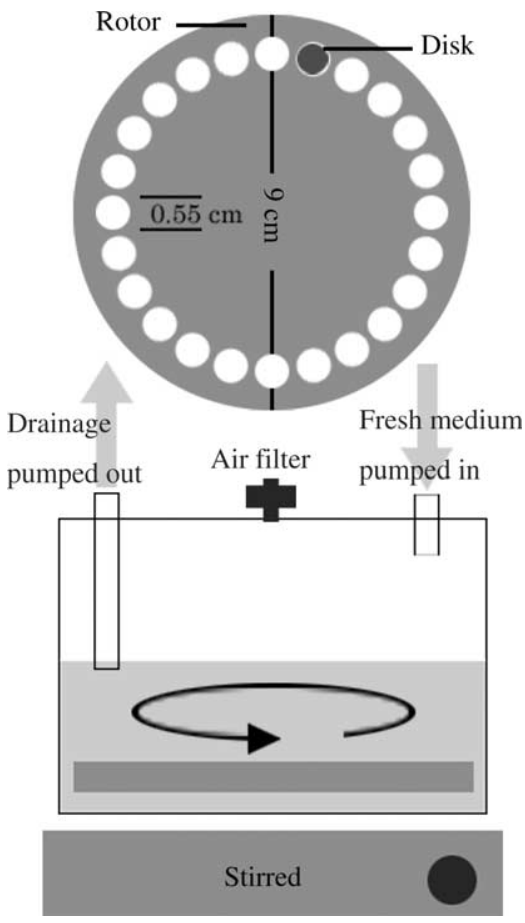

Fig. 1. Schematic drawing of the rotating disk reactor.

\subsection{Biofilm regrowth after $P A C T$}

Biofilms under PACT of $20 \mathrm{mM} \delta$-ALA and $120 \mathrm{~J}$ $\mathrm{cm}^{-2}$ irradiation was chosen for regrowth experiments. After PACT, disks with treated biofilms were moved to a new reactor containing $150 \mathrm{ml}$ sterile $1 / 100$ strength TSB and fed at a dilution rate of $4.1 \mathrm{~h}^{-1}$ with $1 / 100$ strength TSB. Sterile blank disks were also put in the new reactor as control. After $12 \mathrm{~h}$, PACT of $10 \mathrm{mM} \delta$ ALA and 20 min irradiation was applied on biofilms. The regrowth circumstances were recorded every $12 \mathrm{~h}$.

\subsection{Cell enumeration}

Viable-cell numbers were determined by serial dilution and plating on R2A agar (Difco). For total-cell numbers, suitably diluted cell suspensions were stained with $0.01 \%(w / v)$ acridine orange (Sigma) for $1 \mathrm{~min}$ and collected on black polycarbonate filter membranes $(0.2$ $\mu \mathrm{m}$, Millipore, Cork, Ireland) by filtration. Direct cell counts were calculated using an E600 fluorescent microscopy (Nikon, Tokyo, Japan) by averaging ten microscopic fields.

\subsection{Statistical analysis}

All experiments were repeated three times. Statistical analyses were performed with Excel 2002 (Microsoft) and were based upon the log transformational means.

\section{Results}

\subsection{PACT on planktonic cultures}

The $\delta$-ALA mediated PACT on planktonic $P$. aeruginosa is shown in Fig. 2. When samples treated with PS and without exposure to LED, almost all of cells remained viable up to $5 \mathrm{mM}$ of $\delta$-ALA. The survival fraction reduced to $0.26 \pm 0.03,0.053 \pm 0.022$ and $0.0042 \pm 0.0009$ when treated with $7.5,10$ and $12.5 \mathrm{mM}$ of $\delta$-ALA, respectively. When samples were exposed to a light dose of $120 \mathrm{~J} \mathrm{~cm}^{-2}$, no significant reduction in survival fraction was found under $0,2.5,5$ and $7.5 \mathrm{mM}$ of $\delta$-ALA treatment. Significant decrease in survival fraction was observed when 10 and $12.5 \mathrm{mM}$ of $\delta$-ALA were applied. When samples were under exposure to 240
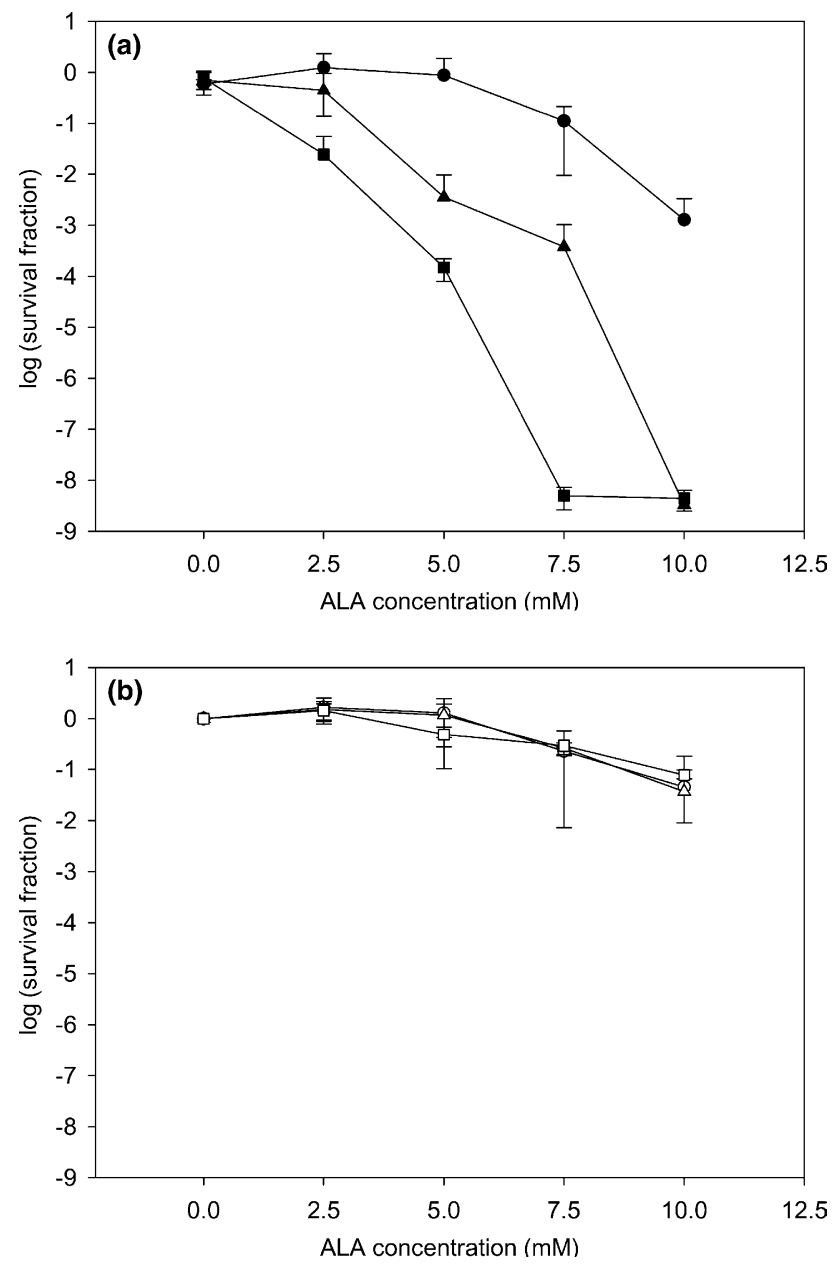

Fig. 2. PACT on $P$. aeruginosa planktonic cultures with (a) and without (b) exposure to LED. Cell concentration about $10^{8}$ cells $\mathrm{ml}^{-1}$ was treated by PACT. After treatment with different $\delta$-ALA concentrations, samples were exposed to $120 \mathrm{~J} \mathrm{~cm}^{-2}$ (solid circle), $240 \mathrm{~J} \mathrm{~cm}^{-2}$ (solid triangle), and $360 \mathrm{~J} \mathrm{~cm}^{-2}$ (solid square). For experiment without LED irradiation, samples were kept in the dark for 20 min (open circle), $40 \mathrm{~min}$ (open triangle), and $60 \mathrm{~min}$ (open square) as controls ( $n=3$, bars indicate standard errors). 
$\mathbf{J ~} \mathrm{cm}^{-2}$, survival fraction decreased significantly as the concentrations of $\delta$-ALA were over $5 \mathrm{mM}$. No viable cells were detected when treated with 10 and $12.5 \mathrm{mM}$ of $\delta$-ALA. This amounted to 8 logs of the cells being inactivated and similar result was also found in the cases of $360 \mathrm{~J} \mathrm{~cm}^{-2}$ exposure. No cells were survived when the concentrations of $\delta$-ALA were more than $7.5 \mathrm{mM}$.

\subsection{PACT on biofilm cultures}

Fig. 3 illustrates the $\delta$-ALA mediated PACT on $P$. aeruginosa biofilms. Without exposure to LED irradiation, the biofilm density did not vary a lot when $\delta$-ALA treatment was less than $10 \mathrm{mM}$. When treated with 20 and $40 \mathrm{mM} \delta$-ALA, about $2-\log$ reduction in biofilm density was observed. When exposed to $120 \mathrm{~J} \mathrm{~cm}^{-2}$, the biofilm density decreased with increasing concentrations of $\delta$-ALA treatment. No viable cells were detected when 20 and $40 \mathrm{mM}$ of $\delta$-ALA were applied. It meant that biofilm density of $(1.16 \pm 0.17) \times 10^{9}$ cells $\mathrm{cm}^{-2}$ all suffered from PACT and could not recover on agar plates.

\subsection{Biofilm regrowth after $P A C T$}

Fig. 4 shows $P$. aeruginosa biofilm regrowth after $\delta$ ALA-mediated PACT. After biofilm samples were treated with $20 \mathrm{mM}$ of $\delta$-ALA and exposed to $120 \mathrm{~J}$ $\mathrm{cm}^{-2}$ light dose, the disks with biofilms were put back into a sterilized reactor and the conditions of biofilm cultivation were resumed. For the disk without PACT, biofilm cell density maintained steady at ca. $9.6 \pm 0.2 \mathrm{log}$

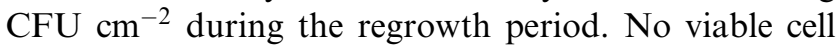
was detected on the PACT-treated disk until $24 \mathrm{~h}$ of regrowth. Biofilms appeared to re-accumulate thereafter

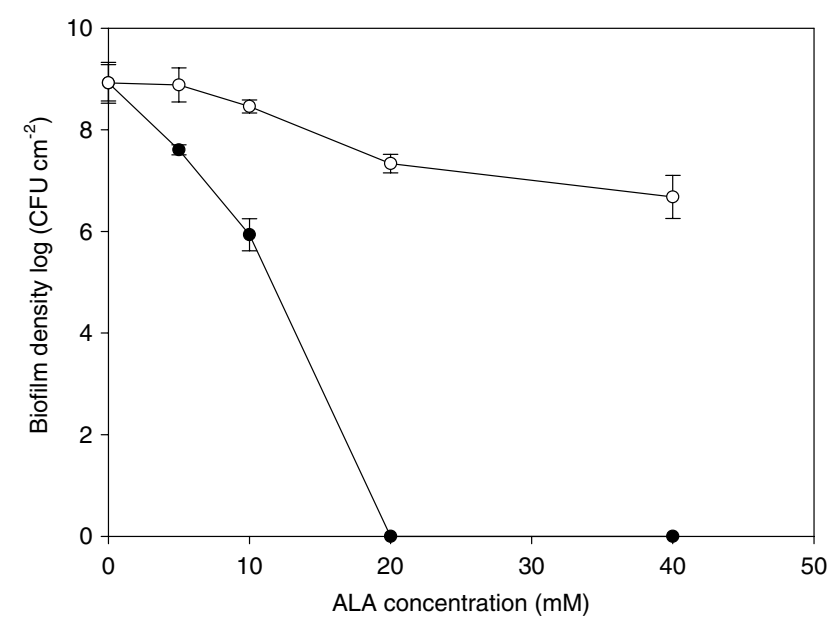

Fig. 3. PACT on P. aeruginosa biofilms. After biofilms were treated with different concentrations of $\delta$-ALA for $1 \mathrm{~h}$, exposure to $120 \mathrm{~J} \mathrm{~cm}^{-2}$ light dose (solid circle) caused biofilm density decreasing which related to $\delta$-ALA concentration. Samples without irradiation were as the control (open circle) ( $n=3$, bars indicate standard errors).

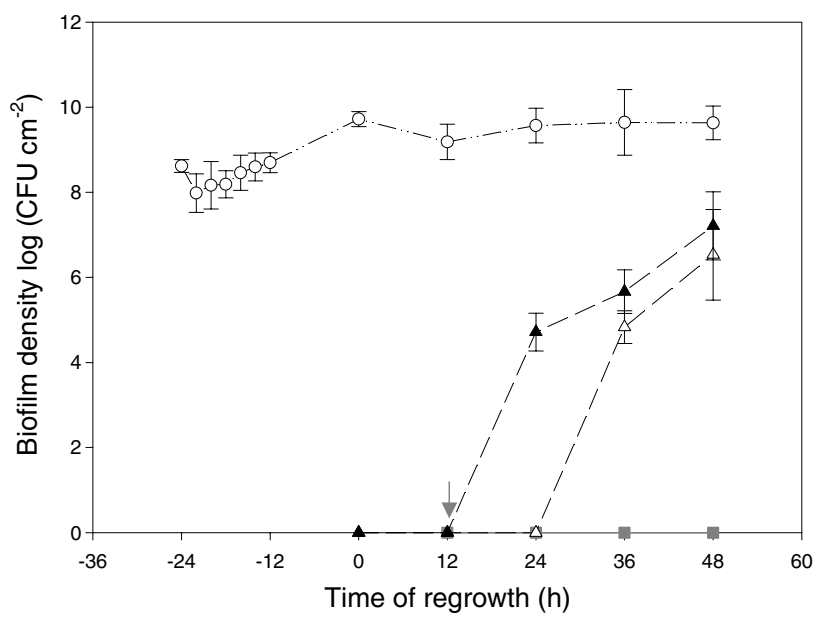

Fig. 4. P. aeruginosa biofilm regrowth after PACT treatment. (open circle): Biofilm cells without PACT; (solid triangle): 24-h-old biofilms after one-time PACT; (open triangle): a sterile blank disk; (gray square): 24-h-old biofilms after one-time PACT, regrowth for $12 \mathrm{~h}$, and followed by another PACT (arrow means the start of the second PACT) ( $n=3$, bars indicate standard errors).

and reached $7.2 \pm 0.8 \log \mathrm{CFU} \mathrm{\textrm {cm } ^ { - 2 }}$ after $48 \mathrm{~h}$ of regrowth. In the meantime, a sterile blank disk was also placed in the regrowth reactor. No biofilm accumulation was observed until some detached cells reattached to the disk at $48 \mathrm{~h}$ of regrowth. To completely eliminate the possibility of regrowth, the PACT treated biofilms were allowed for recover for $12 \mathrm{~h}$, followed by another PACT treatment in a separate experiment. The biofilm was completely eradicated and not a single viable cell was found at the end of experiment.

\section{Discussion}

Biofilms are infamous for their recalcitrance to antimicrobial agents. Mechanisms proposed to explain this enhanced resistance in bacteria within biofilms can be divided into three categories: transport limitation, physiological adaptation and cell-to-cell communication. PACT on biofilms is deemed promising since the mechanism of PDT is irrelative to biofilm recalcitrance. PACT will be effective as long as PS is able to diffuse into the biofilm cells, the light is able to penetrate the biofilm to irradiate PS, and a series of molecular energy transfers occur. Consequently, the energy transfers will lead to the liberation of cytotoxic singlet oxygen from PS, such a release being lethal to many different types of bacterial cell [20]. $\delta$-ALA, an early intermediate in the heme biosynthesis pathway in cell, had no problem in diffusion into $P$. aeruginosa. The red LED used in this study can easily penetrate at least $2 \mathrm{~mm}$ depth of tissue. The result of PACT on planktonic $P$. aeruginosa showed significant photodynamic degradation as expected and was consistent with the finding of Szocs et al. [12]. The 
minor reduction in viable cells without exposure to light may be due to a direct toxicity of high concentration of $\delta$-ALA or interference with $P$ aeruginosa homeostasis.

$\delta$-ALA-mediated PACT on $P$. aeruginosa biofilms seemed potential for medical applications. Most devastating chronic infections are caused by pathogen lived as biofilms. Once a biofilm was formed, it required hundreds of times of antibiotic dose to achieve similar antimicrobial efficacy as in their planktonic counterparts. In this study, no viable biofilm cells were detected after treatment with $20 \mathrm{mM} \delta$-ALA and followed by a $120 \mathrm{~J}$ $\mathrm{cm}^{-2}$ incident dose. When the PACT-treated disk was put back to a sterile reactor, no regrowth of $P$. aeruginosa biofilm cells was observed for the first $12 \mathrm{~h}$. However, regrowth of biofilm cells occurred after $24 \mathrm{~h}$. This observation was quite consistent with the understanding of biofilm recalcitrance. Anwar et al. [21] found regrowth of the $P$. aeruginosa biofilm occurred after the termination of antibiotic therapy. Svensson et al. [22] reported that it was not possible to prevent regrowth of Staphylococcus epidermidis biofilms by increasing antibiotic concentration further. In study of urinary tract infection, Sano et al. [23] also found reproliferation of MRSA occurred immediately after withdrawal of the antimicrobial agent. In our experiments, regrowth was prevented after a pulse-chase-pulse PACT treatment. In other words, it took two rounds of PACT to eliminate the possibility of biofilm regrowth. Although PACT on biofilms seemed promising, further investigation regarding the mechanism of PACT was required.

\section{Acknowledgements}

The financial support of the National Science Council of the ROC (Grant No. NSC91-2320-B-002-198) is greatly appreciated.

\section{References}

[1] D.M. Cochrane, M.R. Brown, H. Anwar, P.H. Weller, K. Lam, J.W. Costerton, Antibody response to Pseudomonas aeruginosa surface protein antigens in a rat model of chronic lung infection, $\mathbf{J}$. Med. Microbiol. 27 (1988) 255-261.

[2] J.W. Costerton, P.S. Stewart, E.P. Greenberg, Bacterial biofilms: a common cause of persistent infections, Science 284 (1999) 13181322 .

[3] J.C. Nickel, I. Ruseska, J.B. Wright, J.W. Costerton, Tobramycin resistance of Pseudomonas aeruginosa cells growing as a biofilm on urinary catheter material, Antimicrob. Agents Chemother. 27 (1985) 619-624.

[4] J.W. Costerton, Z. Lewandowski, D.E. Caldwell, D.R. Korber, H.M. Lappin-Scott, Microbial biofilms, Annu. Rev. Microbiol. 49 (1995) 711-745.

[5] D.G. Davies, M.R. Parsek, J.P. Pearson, B.H. Iglewski, J.W. Costerton, E.P. Greenberg, The involvement of cell-to-cell signals in the development of a bacterial biofilm, Science 280 (1998) 295298.

[6] M. Hentzer, K. Riedel, T.B. Rasmussen, A. Heydorn, J.B. Andersen, M.R. Parsek, S.A. Rice, L. Eberl, S. Molin, N. Hoiby, S. Kjelleberg, M. Givskov, Inhibition of quorum sensing in Pseudomonas aeruginosa biofilm bacteria by a halogenated furanone compound, Microbiology 148 (2002) 87-102.

[7] L. Hall-Stoodley, P. Stoodley, Developmental regulation of microbial biofilms, Curr. Opin. Biotechnol. 13 (2002) 228-233.

[8] J. Davila, A. Harriman, Photosensitized oxidation of biomaterials and related model compounds, Photochem. Photobiol. 50 (1989) $29-35$.

[9] L.E. Bockstahler, T.P. Coohill, K.B. Hellman, C.D. Lytle, J.E. Roberts, Photodynamic therapy for herpes simplex: a critical review, Pharmacol. Ther. 4 (1979) 473-499.

[10] J.M. O’Brien, D.K. Gaffney, T.P. Wang, F. Sieber, Merocyanine 540 -sensitized photoinactivation of enveloped viruses in blood products: site and mechanism of phototoxicity, Blood 80 (1992) 277-285.

[11] J.S. Friedberg, C. Skema, E.D. Baum, J. Burdick, S.A. Vinogradov, D.F. Wilson, A.D. Horan, I. Nachamkin, In vitro effects of photodynamic therapy on Aspergillus fumigatus, J. Antimicrob. Chemother. 48 (2001) 105-107.

[12] K. Szocs, F. Gabor, G. Csik, J. Fidy, $\delta$-Aminolaevulinic acidinduced porphyrin synthesis and photodynamic inactivation of Escherichia coli B, J. Photochem. Photobiol. B 50 (1999) 817.

[13] G. Bertoloni, F.M. Lauro, G. Cortella, M. Merchat, Photosensitizing activity of hematoporphyrin on Staphylococcus aureus cells, Biochim. Biophys. Acta 1475 (2000) 169-174.

[14] M. Wilson, T. Burns, J. Pratten, Killing of Streptococcus sanguis in biofilms using a light-activated antimicrobial agent, J. Antimicrob. Chemother. 37 (1996) 377-381.

[15] S. Wood, B. Nattress, J. Kirkham, R. Shore, S. Brookes, J. Griffiths, C. Robinson, An in vitro study of the use of photodynamic therapy for the treatment of natural oral plaque biofilms formed in vivo, J. Photochem. Photobiol. B 50 (1999) 1-7.

[16] J.F. O'Neill, C.K. Hope, M. Wilson, Oral bacteria in multi-species biofilms can be killed by red light in the presence of toluidine blue, Lasers Surg. Med. 31 (2002) 86-90.

[17] M. Doss, W.K. Philipp-Dormston, Porphyrin and heme biosynthesis from Endogenous and exogenous $\delta$-aminolevulinic acid in Escherichia coli, Pseudomonas aeruginosa, and Achromobacter metalcaligenes, Hoppe Seylers Z. Physiol. Chem. 352 (1971) 725 733.

[18] J.C. Kennedy, R.H. Pottier, Endogenous protoporphyrin IX, a clinically useful photosensitizer for photodynamic therapy, J. Photochem. Photobiol. B 14 (1992) 275-292.

[19] B. Pitts, A. Willse, G.A. McFeters, M.A. Hamilton, N. Zelver, P.S. Stewart, A repeatable laboratory method for testing the efficacy of biocides against toilet bowl biofilms, J. Appl. Microbiol. 91 (2001) 110-117.

[20] S. Pervaiz, Reactive oxygen-dependent production of novel photochemotherapeutic agents, Faseb J. 15 (2001) 612-617.

[21] H. Anwar, J.L. Strap, K. Chen, J.W. Costerton, Dynamic interactions of biofilms of mucoid Pseudomonas aeruginosa with tobramycin and piperacillin, Antimicrob. Agents Chemother. 36 (1992) 1208-1214.

[22] E. Svensson, H. Hanberger, M. Nilsson, L.E. Nilsson, Factors affecting development of rifampicin resistance in biofilm-producing Staphylococcus epidermidis, J. Antimicrob. Chemother. 39 (1997) 817-820.

[23] M. Sano, T. Hirose, M. Nishimura, S. Takahashi, M. Matsukawa, T. Tsukamoto, Inhibitory action of clarithromycin on glycocalyx produced by MRSA, J. Infect. Chemother. 5 (1999) 10-15. 